\title{
Electrocardiographic abnormalities in patients with anorexia nervosa
}

\author{
John Thurston and Peter Marks \\ From Westminster Hospital, London
}

\begin{abstract}
Nine patients with anorexia nervosa are described, 7 of whom have abnormal electrocardiograms. These are contrasted with 2 patients with other psychiatric disorders who had also lost weight through failure to eat, and whose electrocardiograms were normal. The abnormalities occurred in the absence of cardiac disease and with normal serum electrolytes. It is postulated that the abnormalities are mediated through stimulation of sympathetic centres within the hypothalamus and release of catecholamines within the myocardium.
\end{abstract}

It was in 1868 that William Gull $(1868,1874)$ of Guy's Hospital first described, 'a peculiar form of disease' occurring in young women, which he called apepsia hysterica.

In an excellent monograph on what is now known as anorexia nervosa, Dally (1969) defines the disease in the following terms.

I) There must be loss of weight because of active refusal to eat. The weight loss should be at least Io per cent of the premorbid body weight.

2) There must be amenorrhoea of at least three months' duration provided menstruation was previously regular. (This criterion must of course be left out in male patients of whom only 6 were reported in Dally's series compared with I 40 females.)

3) There must be no evidence of schizophrenia, severe depression, or organic disease.

4) The age of onset should lie between II and 35 years.

Dally adds that any unusual finding such as anaemia, vitamin deficiency, or raised sedimentation rate is not compatible with a diagnosis of anorexia nervosa.

The incidence of anorexia nervosa has been variously reported as $\mathrm{I} \cdot 6$ per 100,000 in North-east Scotland (Baldwin et al., 1965), 0.37 per 100,000 in New York State (Gardner et al., 1963), and 0.66 per 100,000 in Camberwell (Wing et al., 1968). This is therefore a rare disease and any one practising physician can only have a small experience of the condition.

Received 25 February 1974.
The purpose of this communication is to review the electrocardiographic abnormalities seen in 9 patients who presented at Westminster Hospital and all of whom fulfilled all the criteria for diagnosis outlined above.

\section{Subjects}

Details of the 9 patients are given in the Table. It will be noted that only one of the patients is a man, which is in keeping with anorexia nervosa being predominantly a disease of women. All 9 patients are between the ages of II and 35 as set out in the diagnostic criteria, and all were Caucasian.

\section{Electrocardiographic abnormalities}

All patients were in sinus rhythm, the rate varying between 42 and 116 beats a minute. Case 2 had nodal escape beats in conjunction with a sinus bradycardia. The most striking abnormality was the frequent occurrence of $T$ wave inversion or flattening and ST segment depression as shown clearly in Fig. I and 2 (Cases 5 and 8). These abnormalities might be considered compatible with the changes of myocardial ischaemia if it were not for the youth of the patients and the complete absence of symptoms related to the cardiovascular system.

Five of the subjects studied had lengthening of the QT interval of a minor degree. None of the patients had U waves.

\section{Blood chemistry}

Serum electrolytes were estimated at the time of recording the electrocardiograms in all 9 patients and the findings were remarkable for their normality; in particular the serum potassium, derangement of which might have accounted for some of the electrocardiographic abnormalities, was always in the normal range (Table). 
TABLE Patients with anorexia nervosa

\begin{tabular}{|c|c|c|c|c|c|c|c|c|}
\hline Case & Sex & Age & $K^{+}$ & $\mathrm{Na}^{+}$ & Urea & $\begin{array}{l}\text { Heart } \\
\text { rate }\end{array}$ & $\begin{array}{l}\text { Electrocardiogram } \\
Q T\end{array}$ & Other abnormalities \\
\hline $\begin{array}{l}1 \\
2 \\
3 \\
4 \\
5 \\
6 \\
7 \\
8 \\
9\end{array}$ & $\begin{array}{l}\text { F } \\
M \\
F \\
F \\
F \\
F \\
F \\
F \\
F\end{array}$ & $\begin{array}{l}16 \\
17 \\
17 \\
17 \\
13 \\
19 \\
16 \\
15 \\
18\end{array}$ & $\begin{array}{l}3 \cdot 7 \\
4 \cdot 9 \\
4 \cdot 2 \\
3 \cdot 7 \\
3 \cdot 5 \\
4 \cdot 3 \\
3 \cdot 6 \\
3 \cdot 7 \\
3 \cdot 9\end{array}$ & $\begin{array}{l}138 \\
148 \\
140 \\
139 \\
141 \\
143 \\
141 \\
143 \\
141\end{array}$ & $\begin{array}{l}24 \\
85 \\
37 \\
38 \\
36 \\
40 \\
50 \\
42 \\
38\end{array}$ & $\begin{array}{r}98 \\
42 \\
116 \\
98 \\
110 \\
76 \\
110 \\
106 \\
104\end{array}$ & $\begin{array}{l}0.36(\mathrm{~N} 0.31) \\
0.46(\mathrm{~N}) \\
0.32(\mathrm{~N} 0.29) \\
0.32(\mathrm{~N}) \\
0.30(\mathrm{~N}) \\
0.36(\mathrm{~N}) \\
0.32(\mathrm{~N} 0.30) \\
0.32(\mathrm{~N} 0.3 \mathrm{I}) \\
0.34(\mathrm{~N} 0.30)\end{array}$ & $\begin{array}{l}\text { T } \downarrow, \text { II, III, aVF; ST } \downarrow \text { II } \\
\text { T flat I, V6, V7, nodal beats } \\
\text { Widespread T flattening } \\
\text { Normal electrocardiogram } \\
\text { Widespread T inversion and ST } \downarrow \\
\text { Normal electrocardiogram } \\
\text { Minor T wave changes } \\
\text { T } \downarrow \text {, II, III, aVF; T flat, V5, V6 } \\
\text { No other changes }\end{array}$ \\
\hline $\begin{array}{l}\text { Patie } \\
\text { A } \\
\text { B }\end{array}$ & $\begin{array}{l}\text { ts with } \\
\text { F } \\
\text { M }\end{array}$ & $\begin{array}{l}\text { starva } \\
23 \\
33\end{array}$ & $\begin{array}{l}\text { cause } \\
3 \cdot 9 \\
4 \cdot 1\end{array}$ & $\begin{array}{l}\text { ther ps } \\
\text { I39 } \\
\text { I35 }\end{array}$ & $\begin{array}{l}\text { atric dis } \\
22 \\
32\end{array}$ & $\begin{array}{l}r s \\
62 \\
50\end{array}$ & $\begin{array}{l}\text { Normal } \\
\text { Normal }\end{array}$ & $\begin{array}{l}\text { 'Severe depression' } \\
\text { 'Schizophrenia' }\end{array}$ \\
\hline
\end{tabular}

$N=$ normal

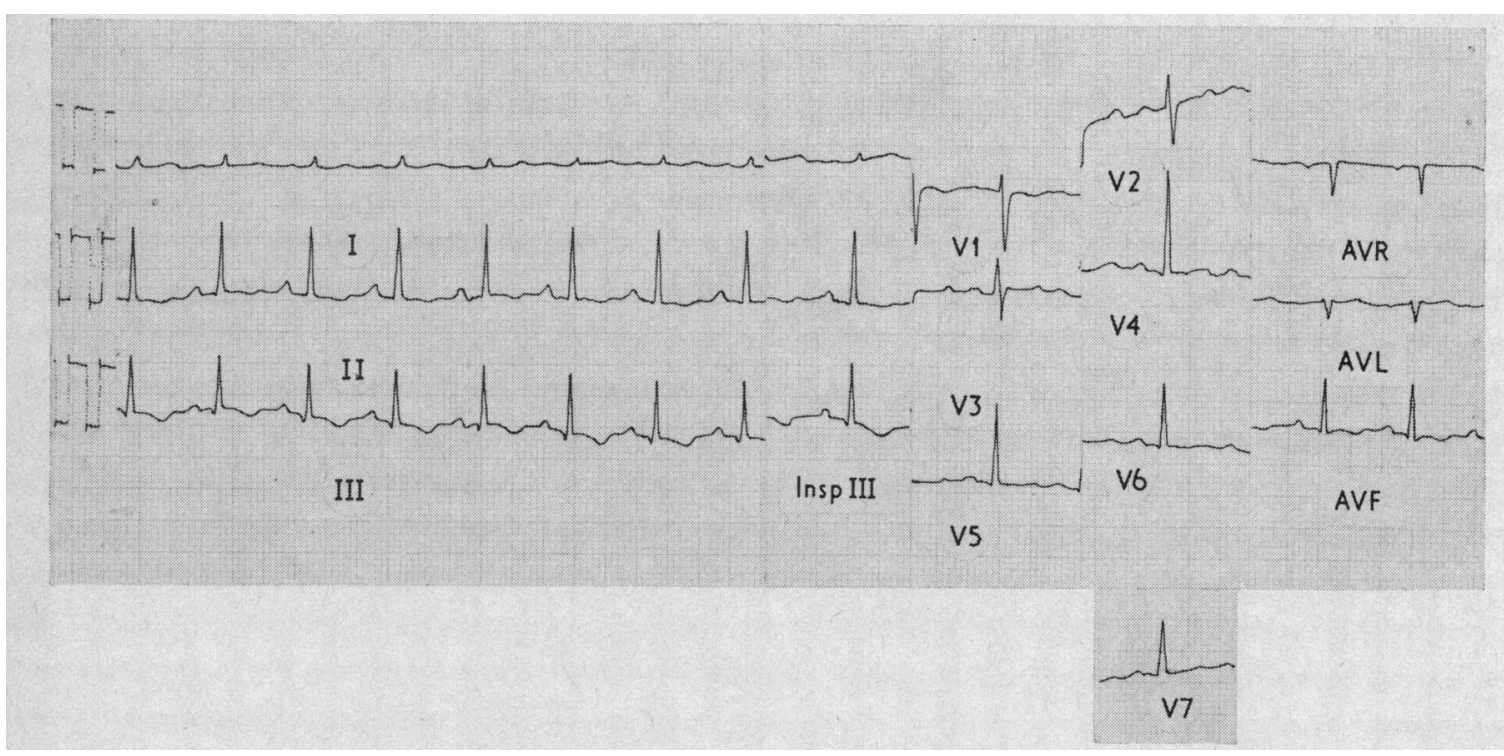

FIG. I Electrocardiogram of Case 8 showing a sinus tachycardia (heart rate 106/minute).

The $T$ waves are inverted in II, III, and $a V F$, and flat in $V_{5}$ and V6.

Two additional patients were initially included as cases of anorexia nervosa when they appeared to fulfil the diagnostic criteria. However both of these have been withdrawn; one, a young woman of 23 who was diagnosed as having amenorrhoea secondary to severe depression, and the other, a man of 33 who had schizophrenia with subsequent starvation. Both of these patients were identical in every other respect to the patients suffering from anorexia nervosa. However, this latter diagnosis was excluded in both cases, the aetiology of the symptom-complex being in the one severe depression and in the other schizophrenia.

It is remarkable that the electrocardiogram in both these patients was normal, since starvation of a severe degree was present in both, and were there any metabolic derangement likely to explain the electrocardiographic abnormalities in anorexia nervosa it surely must have been present in these patients too. 


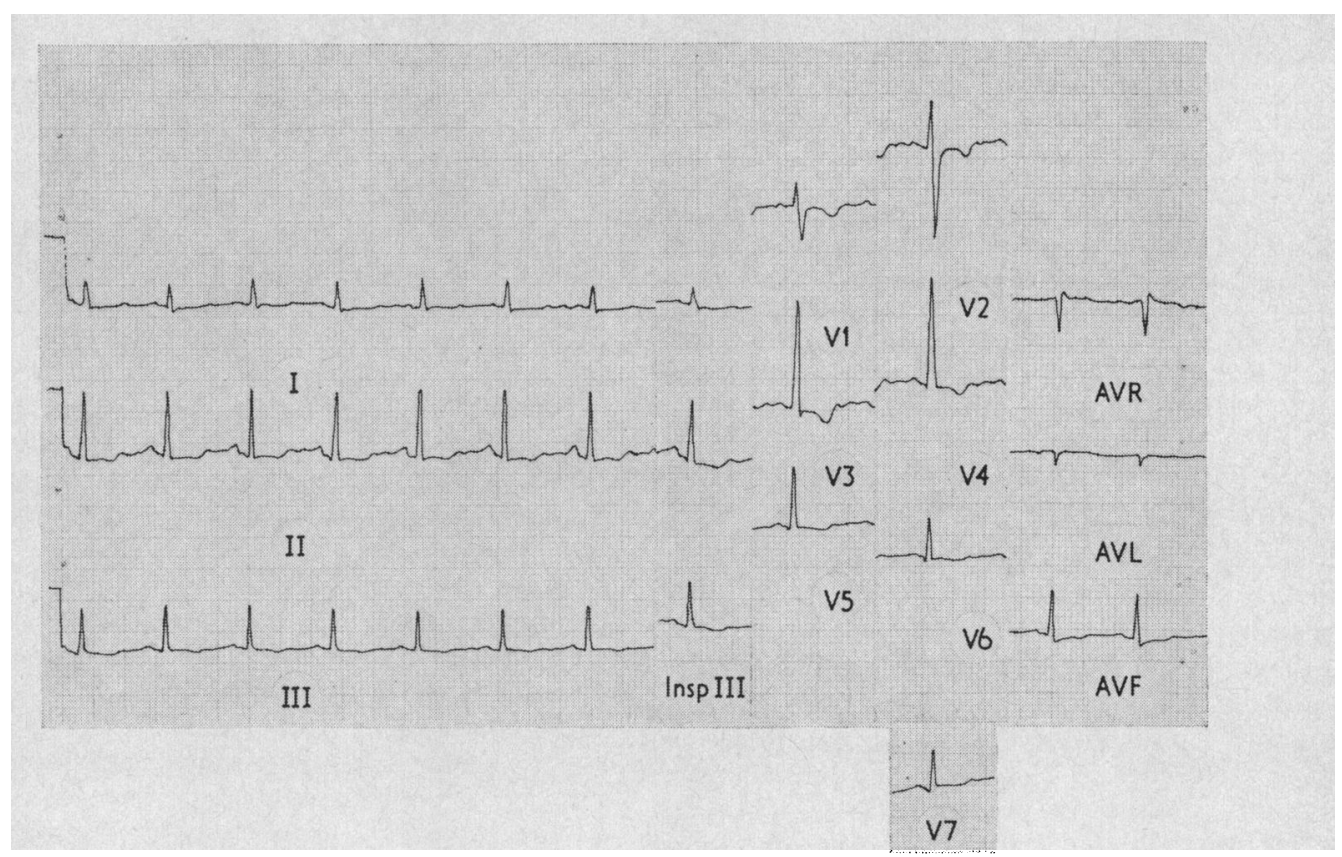

FIG. 2 Electrocardiogram of Case 5 showing a sinus tachycardia (heart rate I Io/minute). There is widespread $T$ wave inversion and $S T$ segment depression.

\section{Discussion}

Anorexia nervosa being a very rare disease it has only been possible to collect 9 patients for study. However it is highly significant that of the 9 patients, 7 had an abnormality on the electrocardiogram. The authors contend that these changes are peculiar to anorexia nervosa, the two patients not suffering from the disease, though metabolically identical, having normal electrocardiograms. Before attributing the electrocardiographic abnormalities to the disease it is essential to eliminate other factors known to produce these abnormalities.

I) Coronary artery disease. The subjects were of an age which makes this unlikely, were women (apart from one), and had no symptoms referrable to the cardiovascular system, and most important of all, the electrocardiograms returned to normal with treatment.

2) Drugs. None of the patients was taking any drugs on admission known to affect the electrocardiogram.

3) Electrolytes. As can be seen from the Table, all electrolyte estimations were normal on admission, as were those of the two patients with other psychiatric disorders. These two patients both had normal electrocardiograms and presumably had similar degrees of starvation. Were there any metabolic abnormality from starvation alone, their electrocardiograms might have been expected to be abnormal to a similar degree.

4) Pericarditis. There was no historical or clinical evidence that any of the 9 patients were suffering from this condition.

5) None of the patients had evidence of cor pulmonale, pulmonary embolism, ventricular hypertrophy, anaemia, or vitamin deficiency. The last two would have precluded the diagnosis of anorexia nervosa as defined above.

6) Electrocardiographic abnormalities have been observed with a number of intracerebral conditions. These include head injury and subarachnoid haemorrhage (Hammermeister and Reichenbach, 1969; Hersch, 1964; Koskelo, Punsar, and Sipila, 1964; Shuster 1960). Friedberg (I967) states,

'Electrocardiographic changes often observed in patients with head injuries, especially those associated with loss of consciousness, should not be misinterpreted as indicating coronary heart disease. In addition to inversion of the $T$ waves in leads V4 to V6 with elevating of the RS - T segments, prolongation of the Q-T interval and increased voltage of the $P$ waves are the most frequent changes. Prominent $U$ waves and sinus arrhythmias are also commonly observed. Striking 
prolongation of the Q-T interval, deeply inverted $T$ waves and prominent $U$ waves have been observed in association with a variety of cerebral disorders, including cerebrovascular accidents, especially with subarachnoid haemorrhage but also with intracranial bleeding. A comparison of the electrocardiographic changes in subarachnoid haemorrhage, meningitis and intracranial space-occupying lesions indicated that an increased Q-T interval and depression of S-T segment occurred only in patients with subarachnoid haemorrhage (Hersch, 1964). A high incidence of tall $P$ and $U$ waves occurred in those with subarachnoid haemorrhage and meningitis, whereas, $T$ wave inversions occurred in all three groups. The electrocardiographic changes have been related to subendocardial haemorrhages in the left ventricle found at autopsy (Koskelo et al., I964).'

The authors feel that the most likely explanation for the electrocardiographic abnormalities found so commonly in anorexia nervosa is an intracranial one. The absence of $U$ waves supports this idea as these waves would be prominent in hypokalaemia and also occur frequently in subarachnoid haemorrhage. In particular the authors postulate that the changes are a result of sympathetic stimulation in the hypothalamus. That there is a connexion between the hypothalamus and anorexia nervosa is widely accepted (Decourt and Michard, 1950; Reifenstein, 1946; Sheldon, 1939), and it is this effect that causes the amenorrhoea essential to the diagnosis in women with the disease. Nerve impulses from the hypothalamus to the anterior pituitary gland are blocked, with the result that luteinizing hormone is not released. Urinary oestrogens are then absent or diminished but urinary gonadotrophins continue to be within normal limits until the degree of starvation is sufficient to diminish the activity of the anterior pituitary.

Barger, Liebowitz, and Herd (r96I) showed that infusion of adrenaline and noradrenaline into a coronary artery of a conscious dog produced electrocardiographic abnormalities without enzyme increases. This suggested that adrenergic reflexes could produce electrocardiographic abnormalities without myocardial damage. Sympathetic stimulation can provide prolongation of the QT interval such as is seen in the anorectic patients in this paper.

Abnormal electrocardiograms are seen in patients with subarachnoid haemorrhage, meningitis, and head injuries. Hypokalaemia is a contributing factor in each of these examples but it is reiterated that hypokalaemia did not obtain in these patients with anorexia nervosa. Hersch (I964) reviewed 60 patients with intracranial abnormalities and found that ST segment depression and QT interval lengthen- ing occurred only in patients with subarachnoid haemorrhage, the changes being seen in 45 per cent of such patients. None of the 9 anorectic patients had any clinical features of subarachnoid haemorrhage.

Shuster (1960) attributed the ST depression in subarachnoid haemorrhage to vagal stimulation. That this is an explanation in the present patient is denied by the fact that 7 of the 9 had a heart rate of 98 or greater, though this might be the explanation in Case 2.

Further evidence of a sympathetic-mediated change in the electrocardiogram is adduced by Porter, Kamikawa, and Greenhoot (I962) who produced $T$ wave inversion by stimulation of the central hippocampus of cats which could be blocked by transection of the cervical spinal cord. Smith and Tomlinson (1954) reported 29 patients with subendocardial haemorrhage in 235 necropsies in patients dying of intracranial disease.

Hammermeister and Reichenbach (1969) describe a patient with electrocardiographic abnormalities and subarachnoid haemorrhage. They come to the conclusion that acute intracranial disease stimulates sympathetic centres in the hypothalamus which results in release of catecholamines within the myocardium. These substances are presumably in sufficient concentration at the myocardial cellular level to cause damage to the contractile apparatus and to the cell membrane, accounting for the electrocardiographic abnormalities.

The patchy focal necrosis of myocardial cells is likely to produce the $T$ wave changes of subendocardial ischaemia or infarction without the development of $Q$ waves which are generally thought to represent transmural damage. Degrees of myocardial necrosis of this minor extent can be very subtle as fibrosis does not develop.

In conclusion the authors feel that the electrocardiographic abnormalities which occur commonly (in their experience) in anorexia nervosa are brought about by stimulation of sympathetic centres within the hypothalamus and the release of catecholamines within the myocardium.

The authors wish to thank Dr. Peter Dally of Westminster Hospital whose patients provided the material for this study and whose monograph on anorexia nervosa was an inspiration and constant guide.

\section{References}

Baldwin, J. A., Innes, G., Millar, W. M., Sharp, G. A., and Dorricott, N. (1965). A psychiatric case register in NorthEast Scotland. British fournal of Preventive and Social Medicine, 19, 38.

Barger, A. C., Liebowitz, M. R., and Herd, J. A. (I96r). Chronic catheterization of the coronary artery: infusion of autonomic drugs in the unanaesthetized dog. Federation Proceedings, 20, ror. 
Dally, P. (1969). Anorexia Nervosa. William Heinemann, London.

Decourt, J., and Michard, J-P. (1950). L'amenorrhée des anorexies mentales. Bulletins et Mémoires de la Société Médicale des Hôpitaux de Paris, 66, 1608.

Friedberg, C. K. (1967). Diseases of the Heart 3rd ed., p. 679. W. B. Saunders, Philadelphia and London.

Gardner, E. A., Miles, H. C., Iker, H. P., and Romano, J. (1963). Cumulative register of psychiatric services in a community. American Fournal of Public Health, 53, 1269.

Gull, W. W. (1868). The address in medicine delivered before the annual meeting of the B.M.A. at Oxford. Lancet, 2, I7I.

Gull, W. W. (1874). Anorexia nervosa (apepsia hysterica. Anorexia hysterica). Clinical Society's Transactions, 7, 22.

Hammermeister, K. E., and Reichenbach, D. D. (1969). QRS changes, pulmonary edema, and myocardial necrosis associated with subarachnoid hemorrhage. American Heart fournal, 78, 94 .

Hersch, C. (1964). Electrocardiographic changes in subarachnoid haemorrhage, meningitis, and intracranial spaceoccupying lesions. British Heart fournal, 26, 785.

Koskelo, P., Punsar, S., and Sipila, W. (1964). Subendo- cardial haemorrhage and electrocardiographic changes in intracranial bleeding. British Medical fournal, I, I479.

Porter, R. W., Kamikawa, K., and Greenhoot, J. H. (1962). Persistent electrocardiographic abnormalities experimentally induced by stimulation of the brain. American Heart fournal, 64, 815.

Reifenstein, E. C. (1946). Psychogenic or hypothalamic amenorrhea. Medical Clinics of North America, 30, I 103.

Sheldon, J. H. (1939). Anorexia nervosa. Proceedings of the Royal Society of Medicine, 32, 738.

Shuster, S. (1960). The electrocardiogram in subarachnoid haemorrhage. British Heart fournal, 22, 316.

Smith, R. P., and Tomlinson, B. E. (1954). Subendocardial haemorrhages associated with intracranial lesions. fournal of Pathology and Bacteriology, 68, 327.

Wing, L., Bramley, C., Hailey, A., and Wing, J. K. (1968). Camberwell cumulative psychiatric case register Part I aims and methods. Social Psychiatry, 3, 116.

Requests for reprints to Dr. John Thurston, Westminster Hospital, Dean Ryle Street, Horseferry Road, London SWIP 2AP. 